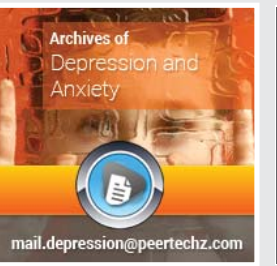

Christopher F Sharpley, Vicki Bitsika, Kimaya Sarmukadam and Linda $L$ Agnew

Brain-Behaviour Research Group, University of New England, Armidale, New South Wales, Australia

Received: 18 June, 2019

Accepted: 30 July, 2019

Published: 31 July, 2019

*Corresponding author: Christopher F Sharpley, Professor, Brain-Behaviour Research Group, School of Science \& Technology, University of New England, Armidale, NSW, 2351, Australia,

E-mail:csharpl3@une.edu.au

Keywords: Job satisfaction; Depression; Subtypes; Hours worked

https://www.peertechz.com

Check for updates
Research Article

\section{Which kinds of work stress are related with which types of depression? Workplace satisfaction and subtypes of depression in rural Australians}

Depression has been shown to have a greater detrimental effect on personal health [1] and costs more in care than other chronic diseases [2]. Depression also brings a risk of mortality that is similar to that from smoking, independently of other contributing factors such as blood pressure, alcohol intake, cholesterol and social status [3]. In fact, people who suffer from depression have a risk of dying from any cause that is nearly twice (1.86 times) that for non-depressed individuals, and nearly 3 million people die from depression annually [4]. Not surprisingly, these individual experiences accumulate to have detrimental effects at the societal or economic levels. For example, depression has been estimated to cost US\$1 trillion globally each year from its effects upon families, workplaces and governments [5]. However, despite these individual and social/economic effects, less than $50 \%$ of sufferers receive treatment [5], and the current available treatments for depression are less than completely efficacious, with the standard pharmacological and psychological treatments most commonly prescribed for depression only providing relief in about $34 \%$ of cases, rising to about $74 \%$ when treatments are combined [6].
It has been suggested that the difficulty in finding a mainstream highly-efficacious treatment for depression is due to the heterogeneity of depression [7]. That is, applying the nine criteria and associated features set out for Major Depressive Disorder (MDD) in the Diagnostic and Statistical Manual of Mental Disorders ( th $^{\text {th }}$ ed.) (DSM-5) [8], produces 1,497 different combinations of symptoms that qualify for the diagnosis of MDD [9]. Consequently, the need for more 'individualised treatment' models of depression diagnosis has been identified as crucial for reducing the damaging effects of depression upon individuals and societies [10,11]. One step towards such an individualised model of diagnosis and treatment of depression is the development of depression 'subtypes'.

Some examples of depression subtyping have included grades of depression severity [12], groups of additional symptoms [13,14], genotyping [15], identification of clusters of specific MDD symptoms and events that may act via genetic and other physiological correlates to predict those symptom clusters $[16,17]$, or via imaging phenotypes [18]. A recent attempt was made to formulate subtypes of depression 
on the basis of a combination of genetic, neurotransmitter, inflammation, and medication response indicators [19], but those authors commented that this process was yet to be realised. Another approach to subtyping depression has been based upon clustering of the clinical symptoms for MDD [20], both in terms of treatment outcomes [21] and neurobiological factors which are associated with different symptoms of MDD $[22,23]$. Based upon a combination of symptom clustering and neurobiological factors, a model of depression subtypes has been developed that included Depressed mood, Anhedonia, Somatic depression, Cognitive depression $[24,25]$. That model has been validated in samples of prostate and breast cancer patients, as well as within several community samples [2628].

As well as seeking to more accurately define depression by identifying subtypes of symptoms, another major focus for research has been into the recognition of depression and its possible contributing factors, with the aim of increasing access to treatment for people who are depressed, or who may be at elevated risk of developing depression. Thus, a great deal of attention has been given to the role that stress plays in the development of depression [29-31], particularly social stress [32], which has been shown to have a physiological influence by changing the blood-brain barrier's effectiveness in preventing access of inflammatory factors to brain regions associated with mood [33]. Although social stress may arise from a variety of sources such as partners, families, and friends, one major venue in which individuals interact socially for most of the day is their workplace [34]. Workplace stress may take the form of interactions with co-workers, as well as the intrinsic aspects of the job itself $[35,36]$. However, although work plays major financial, relationship, and personal satisfaction roles for humans, it has been suggested that a general model of stress is unhelpful in identifying the predictors of stress and job satisfaction in specific job contexts, and that consideration of particular aspects of the workplace or the job itself may help obtain more informed models of work-stress-depression associations [37]. One method of collecting information about the particular aspects of work that may influence an individual's depressive status is by surveying the association between 'job satisfaction' and depression.

Job satisfaction is inversely related to higher workloads, staffing, resources, salary, and having time to balance life and work [38], largely based upon a mismatch between job expectations and actual working environments [39]. Job satisfaction is also correlated with overall stress levels, absenteeism and employee burnout [40-42]. Measurement of job satisfaction has been undertaken for over a century [43], and has included such aspects of work as salary [44], ability to influence the way the job is designed [45], and how well the individual 'fits' the organisation in which they are employed [46]. One survey process that has been applied nationally in Australia has focussed upon satisfaction with salary, job security, nature of the work done, hours worked, and the ability of the individual to balance their work-life commitments [47], and has established validity via Kappa statistics indicating moderate to good agreement (.50 to .71) between individualand JEM-assigned exposures for job demands, control, job insecurity and fairness of pay; internal consistency (Cronbach's alpha) was between .70 and .82 [48]. However, previous work within that study has not reported on the association between overall job satisfaction and subtypes of depression. Similarly, no previous reports were identified that examined the links between various aspects of job satisfaction and subtypes of depression. This kind of more detailed information is necessary to build a model of the association between job satisfaction and depression that 'drills down' to the specific aspects of work that are related to specific subtypes of depression. Information from such an investigation could provide more focussed intervention and individualised treatment that follows the recommendations for 'personalised medicine' approaches in treating depression [10].

Therefore, the current study was designed to investigate the association between job satisfaction and depression at global levels (i.e., total job satisfaction, total depression) and also at the item level for job satisfaction and for the four subtypes of depression discussed above [24]. As part of a series of investigations into the mental health of a selected region in rural Australia, participants were recruited from that region rather than one of the capital cities.

\section{Methods}

\section{Participants}

To ensure that the sample size was sufficient to detect a meaningful association, a priori power analysis (G-Power 3) was conducted for Pearson correlational analysis, and indicated that a sample of 88 would be satisfactory to detect a medium sized effect of .3 [49], with alpha probability of .05 and power of .90. Therefore, recruitment continued until this number of usable datasets had been received. Participants were recruited from the New England region of New South Wales, Australia, via an invitational letter to a random selection of 2,000 residents who were registered on the Australian Electoral Roll, balanced for sex

\section{Instruments}

Background variables measured included gender, age, average hours worked per week on employed work, type of job (using the Australian and New Zealand Standard Classification of Occupations, 2013, Version 1.2) [50], and average hours per week on volunteer work excluding caring for others.

Job satisfaction (JS) was measured using the six-item HILDA survey scale that asks respondents about their satisfaction with: total pay, job security, the work itself, hours worked, and the flexibility available to balance work and non-work commitments, plus a global item for overall job satisfaction. This scale has demonstrated validity and was derived from similar scales in the UK and Germany, and has been widely used and reported as an index of job satisfaction in Australia [51]. Internal consistency (Cronbach alpha) data from the current study are reported below under Results. In this study, respondents answered the six questions about job satisfaction on a five-point scale, where 1 = "Very Low Job Satisfaction", 2 = "Low", 3 = "Moderate", 4 = "High", and 5 = "Very High Job Satisfaction". Raw scores ranged from 6 to 30 
Depression was assessed from the Zung Self-rating Depression Scale (SDS) [52], which consists of 20 items drawn from the DSM-series diagnostic criteria for MDD. Respondents indicate the frequency of each of those 20 items by answering: "None or a little of the time", "Some of the time", "Good part of the time", or "Most or all of the time", which produce numerical scores of 1 to 4 , providing total raw scores from 20 to 80 . SDS raw scores of 40 or above indicate the presence of "clinically significant depression" [53]. The SDS has demonstrated split-half reliability of .81, .79 [52,54] and .94 [55]. Internal consistency (Cronbach alpha) has been reported as .88 for depressed patients and .93 for non-depressed patients [56] and as .84 for a previous Australian sample. The SDS has been shown to be superior to the MMPI Depression Scale and the Beck Depression Inventory for assessing depression in male psychiatric inpatients [56]. SDS raw scores were used in this study.

\section{Procedure}

From a list of 20,000 random names and addresses (balanced for equal numbers of males and females) supplied by the Australian Electoral Commission, sufficient participants were recruited to exceed the sample size required for Pearson correlational analysis, as described above (i.e., $n=88$ ). A total of 179 persons were contacted to achieve this recruitment target. Although equal numbers of males and females were contacted, the final sample was nearly three-quarters female (Table 1). These participants received a link to an online portal or a copy of the questionnaire booklet containing an explanatory statement and consent form, plus the background questionnaire and the JS and SDS. The project was approved by the University of New England Human Research Ethics Committee. All participants gave written consent to the study.

\section{Statistical analyses}

Data were analysed via SPSS v23, and tested for normality. Pearson correlation coefficients were calculated to test for any significant age effects on JS or SDS total scores, and gender was also tested for its effect on these variables via MANOVA. Pearson correlations and Hierarchical regression were used to identify which SDS items made the greatest contribution to specific aspects of JS. Although $p<.05$ was set as the standard for significance, Bonferroni corrections were made to $p$ values to counter the effects of family-wise error where appropriate.

\section{Results}

\section{Data}

The $5 \%$ means were very close to the actual means, suggesting that effects from outliers were minimal. Inspection of the histograms, normal Q-Q plots, and the detrended $\mathrm{Q}-\mathrm{Q}$ plots, indicated that the SDS and JS scores were within normal parameters. The Kolmogorov-Smirnov statistic confirmed this for the SDS, although the JS was skewed to the more positive end of the distribution. However, this slightly minor degree of non-normality is not a necessary source of confound for MANOVA [57], correlational analyses [58], or regression [59]. The internal consistency (Cronbach alpha) of the SDS was .878, acceptable for further analysis. The six JS items had a Cronbach alpha of only .648 , which is not unusual for a quite small scale such as this one [60].

Table 1 presents the demographic data on the total sample of 88 participants, comprised of 25 males $(28.4 \%)$ and 63 females (71.6\%). All data are very similar across males and females, and MANOVA (using Pillai's Trace and the Type II Sum of Squares model due to the disparate cell size for sex) [61], confirmed that there was no significant main effect for sex, $F(7,83)=.421, p=$ .887 , partial eta squared $=.036$, nor any significant univariate effects, thus allowing male and female data to be combined for further analyses. The large standard deviation scores for average hours worked on unpaid work reflected the wide range in participants' responses to this question (males: from 0 to 42hr; females: from 0 to $50 \mathrm{hr}$ ). Types of job reported [50], included (in rounded figures): Managers $=13.6 \%$, Professionals $=44.3 \%$, Technicians \& Trades $=9.0 \%$, Community \& Personal Service $=6.9 \%$, Clerical \& Administration $=22.8 \%$, Sales $=$ $2.3 \%$, Machinery \& Drivers $=1.1 \%$, thus providing a sample that included all these occupational categories.

\section{Job satisfaction and depression}

\section{Global depression score level}

Table 2 presents the Pearson correlation coefficients between the total SDS score and the overall JS score and its individual items. Although there was no significant correlation between SDS total and JS overall satisfaction, there was a significant correlation between SDS total score and the two JS items Hours worked and Flexibility to balance work and non-work commitments at the adjusted $p$ value of .05/6 $=.008$. When the two JS items that were significantly correlated with SDS total score were entered into a hierarchical regression in order of their correlation coefficient size, the entire regression equation was significant, $\mathrm{R}$ square $=.238, F(2,82)=12.465, p<.001$, but only Hours worked $\mathrm{R}$ square change $=.234, F(1,81)$ for change $=$ $24.750, p<.001$, made a significant contribution to the variance in SDS total score, with Flexibility to balance work and non-work commitments only making a very small and nonsignificant additional contribution to the SDS total score variance, $\mathrm{R}$ square change $=.004, F(1,80)$ for change $=0.372, p=.544$. Not surprisingly, both of these aspects of JS were also significantly

Table 1: Means (Standard Deviation) for demographic and scale data $(n=88)$.

\begin{tabular}{|c|c|c|c|c|c|c|c|c|c|c|}
\hline \multirow[b]{2}{*}{ Variable } & \multirow[b]{2}{*}{ Age (years) } & \multirow{2}{*}{$\begin{array}{l}\text { Average hours } \\
\text { worked (paid) }\end{array}$} & \multirow{2}{*}{$\begin{array}{c}\text { Average hours } \\
\text { worked } \\
\text { (unpaid) }\end{array}$} & \multirow{2}{*}{$\begin{array}{l}\text { SDS }^{1} \text { total } \\
\text { score }\end{array}$} & \multicolumn{6}{|c|}{ Job Satisfaction rating 1 to $5^{2}$} \\
\hline & & & & & Salary & Job security & Actual work & $\begin{array}{c}\text { Hours } \\
\text { worked }\end{array}$ & $\begin{array}{c}\text { Flexibility to } \\
\text { balance }\end{array}$ & $\begin{array}{c}\text { Overall } \\
\text { satisfaction }\end{array}$ \\
\hline Males & $45.9(15.1)$ & 34.4 (14.5) & $8.2(10.6)$ & 39.4 (7.9) & $3.4(1.0)$ & $3.4(1.1)$ & $3.8(0.7)$ & $3.5(1.1)$ & $3.8(1.2)$ & $3.7(0.9)$ \\
\hline Females & $41.8(13.1)$ & 30.1 (13.2) & $9.8(13.8)$ & $37.4(6.3)$ & $3.5(0.8)$ & $3.5(1.0)$ & $3.9(0.9)$ & $3.5(0.9)$ & $3.8(0.9)$ & $3.9(0.7)$ \\
\hline
\end{tabular}

SDS $=$ Self-rating Depression Scale; ${ }^{2} 1=$ Very Low, $5=$ Very High. 
correlated with each other $(r=.509, p<.001)$, reflecting the role that work-related time demands has upon participants' ability to include other non-work activities in their lives. There were no significant correlations between hours on unpaid work and SDS total score or the JS overall score.

\section{Depression subtype level}

Table 2 also presents the Pearson correlation coefficients for the four SDS subtypes and the six JS items. For the SDS subtype scores, only Hours worked was significantly correlated at the adjusted $p$ value of $.05 / 24=.0021$ with both of the depression subtypes Depressed mood, and Somatic depression, although there was a nonsignificant trend for Flexibility to balance work and non-work commitments with Somatic depression ( $r$ $=.303, p=.005$ ). Even if the latter trend was considered (vs the adjusted $p$ value of .0021), apart from the five relatively isolated correlations described above and shown in Table 2, the remaining JS items were only very weakly associated with either SDS total score or the four SDS subtypes, accounting for less than $6 \%$ of the variance. There were no significant correlations between hours unpaid work and any of the SDS subtype scores, but there was a sole significant correlation between the JS item for Salary and average number of hours unpaid work $(r=-.349$, $p=.005)$, which may suggest that their unpaid work prevented some participants from earning sufficient income from their paid work.

As a further test of the effects of Hours worked upon depression, the sample was subgrouped into those whose satisfaction with their hours worked was less than or equal to a response of "Moderate" $(n=42)$ versus those who were satisfaction with the hours they worked was "high" or "very high" $(n=46)$. ANOVA on SDS total score was significant $F(1,87)$ $=11.156, p=.001$, partial eta squared $=.121$. When the same subgrouping was applied to a MANOVA on the four subtypes of depression, there was a significant main effect $F(4,83)=$
2.820, $p=.031$, partial eta squared $=.126$, but the univariate analyses revealed significant effects for Somatic depression ( $F$ $=9.448, p=.003$, partial eta squared $=.104)$ and Depressed $\operatorname{mood}(F=4.134, p=.045$, partial eta squared $=.049)$, but not for Anhedonia $(F=0.676, p=.413)$ or Cognitive depression $(F=$ $0.000, p=.992)$. These results confirm the isolation of JS hours worked effects to just these two subtypes of depression.

\section{SDS items and JS items}

Although the four SDS subtypes already represent specific groups of MDD symptoms, there is some heterogeneity remaining in the actual SDS items that comprise each of those subtypes. Therefore, to identify the precise aspects of depression that were active in the significant association between Hours worked and Depressed mood and Somatic depression, Pearson correlation coefficients were calculated for the SDS items that comprise those two depression subtypes, and appear in Table 3. Coefficients that met the adjusted $p$ value of .008 are starred. Because there were two SDS items that met this criterion within each subtype, hierarchical regression was performed on each set of two items. (This kind of 'reverse' regression equation allows for comparisons between the strength of the associations between two sets of variables independently of their implied 'causality', and is superior to running two independent regression analyses [62]). For Depressed mood, the entire equation was significant $(\mathrm{R}$ square $=.207, F(1,82)$ $=10.426, p<.001$ ) and SDS item 1 (I feel downhearted and blue) made a significant contribution to the variance in JS Hours worked $(\mathrm{R}$ square for change $=.179, F$ for change $=17.668, p<$ .001) but SDS item 20 (Others would be better off if I were dead) did not make a significant contribution to the variance in Hours worked $(\mathrm{R}$ square for change $=.028, F$ for change $=2.794, p$ $=$. 099). For Somatic depression, the entire equation was also significant $(\mathrm{R}$ square $=.412 F(1,82)=8.160, p=.001)$. SDS item 4 (I have trouble sleeping at night) made a significant contribution to the variance in JS Hours worked ( $\mathrm{R}$ square for change $=.137$,

Table 2: Pearson correlation coefficients (and $p$ values) between Self-rating Depression Scale (SDS) total score ${ }^{1}$ and subtypes and Job Stress (JS) items ${ }^{2}$.

\begin{tabular}{|c|c|c|c|c|c|c|}
\hline SDS subtype/JS items & Salary & Job security & Actual work & Hours worked & Flexibility to balance & Overall satisfaction \\
\hline SDS total score & $\begin{array}{l}-.236 \\
(.032)\end{array}$ & $\begin{array}{l}-.024 \\
(.830)\end{array}$ & $\begin{array}{c}.009 \\
(.938)\end{array}$ & $\begin{array}{c}-.484^{\star} \\
(.00004)\end{array}$ & $\begin{array}{l}-.311^{\star} \\
(.004)\end{array}$ & $\begin{array}{l}-.180 \\
(.103)\end{array}$ \\
\hline Depressed mood & $\begin{array}{l}-.013 \\
(.904)\end{array}$ & $\begin{array}{l}-.007 \\
(.952)\end{array}$ & $\begin{array}{l}-.003 \\
(.979)\end{array}$ & $\begin{array}{l}-.329 \star \\
(.002)\end{array}$ & $\begin{array}{l}-.058 \\
(.604)\end{array}$ & $\begin{array}{l}-.082 \\
(.462)\end{array}$ \\
\hline Anhedonia & $\begin{array}{l}-.173 \\
(.118)\end{array}$ & $\begin{array}{l}-.076 \\
(.495)\end{array}$ & $\begin{array}{c}.123 \\
(.269)\end{array}$ & $\begin{array}{c}.160 \\
(.149)\end{array}$ & $\begin{array}{l}-.231 \\
(.036)\end{array}$ & $\begin{array}{l}-.057 \\
(.607)\end{array}$ \\
\hline Somatic depression & $\begin{array}{l}-.224 \\
(.042)\end{array}$ & $\begin{array}{l}-.040 \\
(.721)\end{array}$ & $\begin{array}{l}-.103 \\
(352)\end{array}$ & $\begin{array}{l}-.405^{\star} \\
(.0001)\end{array}$ & $\begin{array}{l}-.303 \\
(.005)\end{array}$ & $\begin{array}{l}-.203 \\
(.066)\end{array}$ \\
\hline Cognitive depression & $\begin{array}{l}-.025 \\
(.823)\end{array}$ & $\begin{array}{c}.159 \\
(.151)\end{array}$ & $\begin{array}{l}-.019 \\
(.862)\end{array}$ & $\begin{array}{l}-.021 \\
(.851)\end{array}$ & $\begin{array}{c}.074 \\
(.504)\end{array}$ & $\begin{array}{c}.098 \\
(.380)\end{array}$ \\
\hline
\end{tabular}

'Adjusted $p$ value $=.05 / 6=.008 ;{ }^{2}$ Adjusted $p$ value $=.05 / 24=.0021$.

Table 3: Correlation coefficients between items for Hours worked, and Depressed mood and Somatic depression.

\begin{tabular}{|c|c|c|c|c|c|c|}
\hline Depressed mood & Downhearted and blue & Crying spells & Feel hopeful (reverse) & Irritable & Useful \& needed & Others better off if I were dead \\
\hline Hours worked & $-.423^{\star}$ & -.240 & -.140 & -.263 & -.253 & $-.391 *$ \\
\hline Somatic depression & Trouble sleeping & Losing weight & Constipation & Heart beats fast & Tired for no reason & Restless \\
\hline Hours worked & $-.371 *$ & -.200 & -.039 & -.328 & -.206 & $-.308^{*}$ \\
\hline
\end{tabular}

${ }^{*}$ Adjusted $p$ value $(.05 / 6)=.008$. 
$F$ for change $=12.889, p=.001$ ) but SDS item 13 (I am restless and can't keep still) did not make a significant contribution to the variance in Hours worked ( $\mathrm{R}$ square for change $=.032, \mathrm{~F}$ for change $=3.089, p=.083$ ). Figure 1 portrays the significant associations between Hours worked and the two specific MDD symptoms, and between Flexibility to balance work and nonwork commitments and Feeling downhearted and blue but not for Trouble sleeping at night. Figure 1 also shows how Hours worked significantly predicted Flexibility to balance work and non-work commitments.

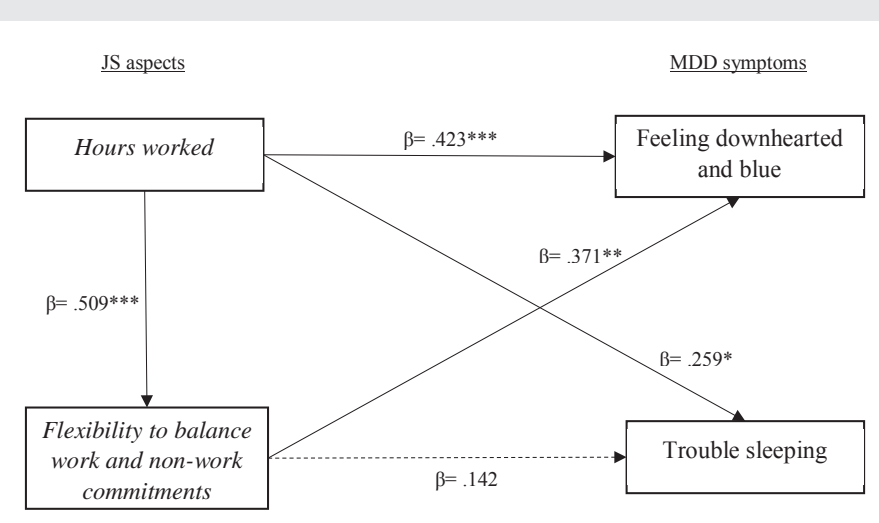

${ }^{*} \mathrm{p}<.05 ; * * \mathrm{p}<.01 ; * * * \mathrm{p}<.00$

Figure 1: Schematic representation of Job Stress (JS) aspects that significantly predict Major Depressive Disorder (MDD) symptoms.

\section{Discussion}

These results help to clarify which aspects of Job Satisfaction are significantly associated with depression at global, subtype, and individual symptom levels. At a global depression level, dissatisfaction with the number of hours worked per week was a significant predictor of total depression scores on the SDS, but other aspects of JS were not significantly associated with total depression score, nor was total JS score significantly correlated with total SDS score. These findings suggest that, from the factors measured by the JS, it was only one specific aspect of a person's satisfaction with their job that potentially contributed to their overall depressive state in this sample. It is of interest that satisfaction with the number of hours they worked also contributed to participants' inability to balance their work vs non-work life demands, but that the latter was not a singular significant contributor to SDS total or subtype scores. As suggested in Figure 1, the key factor may be satisfaction with hours worked, which contributes to depression and also to participants' dissatisfaction with their ability to balance their work and non-work commitments. As such, satisfaction with the sheer amount of time participants spent at their paid employment appears to be the key factor in this sample, with the consequent reduction in time for other activities also contributing to their feelings of sadness.

However, when examined at the depression subtype level, only depressed mood and Somatic depression were significantly influenced by dissatisfaction with hours worked, although there was also a trend for dissatisfaction with ability to balance work and non-work demands to also influence these two subtypes of depression. Further clarity of these relationships was provided by the analysis of SDS items and JS items. It is of note that Feeling downhearted and blue is one of the two key required DSM- 5 symptoms for a diagnosis of MDD (i.e., feeling sad or crying; loss of interest and pleasure in most activities) [8], and this holds some importance in terms of the overall depressive state of individuals. Dissatisfaction with hours worked was also significantly associated with participants' difficulties sleeping (a Somatic depression symptom) but not with the psychomotor symptom of restlessness and agitation. These results are quite specific, and suggest a concise model of the association between JS and depression in the current sample, one that appears to be described by just a single aspect of JS and two MDD symptoms, as shown in Figure 1. The significant association between Hours worked and Flexibility to balance work and non-work commitments (Figure 1) also suggests that these two aspects of JS are related (as they would be expected to be on a logical basis), and may interact to predict depression.

Thus, the major finding from this study is that participants' dissatisfaction with the amount of time they spent on paid work appeared to influence their depressive status overall, and their Depressed mood and Somatic depression, and that this effect was most strongly apparent in their feelings of being downhearted and blue. This isolation of a specific aspect of JS to just one of the two key diagnostic criteria for MDD holds implications for treatment because Depressed mood is largely a function of reduced serotonin release and uptake [63]. These reductions in available serotonin in the brain influence core behavioural functions [64], and may predispose the individual to an expectancy of aversive experiences. but no change in expectancy of pleasant experiences, in the future $[65,66]$. That change to focus more upon a negative future than a positive future may explain the behavioural withdrawal from the stressful environment which is characteristic of depression and which may contribute to the likelihood of death or suicide that is present in a proportion of depressed cases [67]. Treatment options for Depressed mood include those that re-establish serotonergic function if required, such as antidepressants [68], although that may be insufficient in itself [69], and may need to be augmented by environmental enrichment via psychotherapy [70].

In terms of the consequences of the current findings upon employees and workplaces, the significant interaction between dissatisfaction with hours worked and the lack of flexibility to engage in non-paid work responsibilities is a logical outcome in that the number of hours available for these two sets of tasks is limited, but the unfortunate depressive effect that dissatisfaction with longer working hours may have upon employees' inability to 'balance' their lives in terms of completing their non-paid work tasks may also have a downstream effect upon their ability to work effectively, or even to attend at work. In their major systematic review of the effects of depression upon workplace productivity [71], found that depressed persons who are employed also show significantly higher rates of 'presenteeism' (being at work but not productive between $35 \%$ and $60 \%$ of the time) and 
absenteeism (missing work an average of four days/month). These effects from depression were estimated by [72], to cost USA industry about US\$51 billion in 2008 terms.

There are two possible interpretations of these data in terms of workplace conditions. First, from a workplace perspective, if the dissatisfaction reports from participants are given credit, then workplaces that encourage or require high numbers of working hours from their employees than they may wish to give may be likely to experience higher rates of Depressed mood and Somatic depression in those employees, particularly if those high working hours prevent employees from actively engaging in their other non-paid work activities for which they feel a responsibility. A great deal of previous research has examined the detrimental effects on employees of high work demands $[73,74]$, but more recent data suggest that some employees might enjoy an increase in their work hour demands to earn more income [75]. Secondly (and alternatively) from an employee perspective, if the participants' reports on their dissatisfaction with the number of hours they work are a reflection of either their (a) undertaking too much work, or (b) undertaking normal working hours but not being able to manage with that load, then these employees may need to adjust their expectations of their own optimum workload, or consider adjusting the type of work that they do. Regardless of which of these effects was present in the current data, Job Satisfaction is largely based upon a mismatch between job expectations and actual working environments [39], and it may be that there was some degree of this kind of mismatching present within the workplace settings of some of the current participants, whether that was due to some employees wanting fewer work hours, or some wanting more work hour demands. The presence of such mismatching in the current sample is congruent with previous data indicating that $40 \%$ of people across seven OECD nations reported that they are not working the hours they would prefer [76]. Consequently, moves towards individualised work-assignment practices have been suggested [77] and found to increase employee Job Satisfaction and reduced absenteeism [78].

Limitations of the current study include the culture and location of the sample which restricts generalisability to other settings and cultures, the lack of longitudinal data which may have provided a restricted 'snapshot' of the field, the selfreport nature of the data-collection methodology instead of clinical diagnoses of depression, and the restriction of JS data to just a six-item scale. Strengths of the study include use of a scale for JS that has been widely used in Australia over several years and had established validity and reliability, a self-report scale for depression that has good psychometric properties, a satisfactory sample size based upon a priori power calculations, and the focus upon a specific region of Australia. Data from studies such as this inform specific research questions around regional issues, and do not attempt to represent the entire society or nation.

Despite these limitations, these findings provide a clearer understanding of how specific aspects of job satisfaction contribute to the depressive state of employees, and what form that depression takes. These results can therefore be of use when formulating possible employee assistance schemes, as well as the clinical treatment of depression that may arise from job stress. As such, they contribute to the ongoing trend towards individualised medicine approaches for diagnosis and treatment of depression.

\section{References}

1. Moussavi S, Chatterij S, Verdes E, Tandon A, Patel V et al. (2007) Depression, chronic diseases, and decrements in health; results from the World Health Surveys. Lancet 370: 851-858. Link: https://bit.ly/2yoZhA6

2. Langa KM, Valenstein MA, Fendrick AM, Kabeto MU, Vijan S (2004) Extent Cost of Informal Caregiving for Older Americans With Symptoms of Depression. American Journal of Psychiatry 161: 857-863. Link: https://bit.ly/2KgMuFd

3. Mykletun A, Bjerkeset O, Øverland S, Prince M, Dewey M et al. (2009) Levels of anxiety and depression as predictors of mortality: the HUNT study. British Journal of Psychiatry 195: 118-125. Link: https://bit.ly/2Mowvru

4. Walker E, Mcgee R, Druss B (2015) Mortality in mental disorders and global disease burden implications: A systematic review and meta-analysis. JAMA Psychiatry 72: 334-341. Link: https://bit.ly/2LQ5dul

5. WHO (2017) Depression: "Let's talk" says WHO, as depression tops list of causes of ill health. Geneva: World Health Organisation. Link: https://bit.ly/2rsqQoP

6. Rush A, Trivedi M, Wisniewski S, Nierenberg A, Stewart J, et al. (2006) Acute and longer-term outcomes in depressed outpatients requiring one or several treatment steps: a STAR* report. American Journal of Psychiatry 163: 1905 1917. Link: https://bit.ly/2MrlFRr

7. Monroe S, Anderson S (2015) Depression:The Shroud of Heterogeneity. Current Directions in Psychological Science 24: 227-231. Link: https://bit.ly/2K4osyl

8. APA (2013) Diagnostic and statistical manual of mental disorders (5th ed.), Washington, DC, American Psychiatric Association.

9. Ostergaard S, Jensen S, Bech P (2011) The heterogeneity of the depressive syndrome: When numbers get serious. Acta Psychiatrica Scandinavia 124: 495-496. Link: https://bit.ly/2SQY7Xk

10. Insel T (2013) Transforming diagnosis [Online]. USA: National Institute of Mental Health. Link: https://bit.ly/2x6yrPc

11. Kapur S, Phillips A, Insel T (2012) Why has it taken so long for biological psychiatry to develop clinical tests and what to do about it? Molecular Psychiatry 17: 1174-1179. Link: https://bit.ly/2uAtNHn

12. Judd LL, Akiskal HS, Maser JD, Zeller PJ, Endicott J et al. (1998) A prospective 12-yar study of subsyndromal and syndromal depressive symptoms in unipolar major depressive disorders. Archives of General Psychiatry 55: 694700. Link: https://bit.ly/2ZjitLj

13. Parker G (2005) Beyond major depression. Psychological Medicine 41: 467 474. Link: https://bit.ly/2YzmluD

14. Parker G, Roy K, Mitchell P, Wilhelm K, Malhi G, et al. (2002) Atypical depression: a reappraisal. American Journal of Psychiatry 159: 1470-1479. Link: https://bit.ly/314cYAK

15. Yu C, Arcos-Burgos M, Licinio J, Wong M-L (2017) A latent genetic subtype of major depression identified by whole-exome genotyping data in a MexicanAmerican cohort. Translational Psychiatry 7: e1134. https://go.nature. com/3142sth

16. Fried E, Nesse R (2015) Depression is not a consistent syndrome: An investigation of unique symptom patterns in the $S T A R^{\star} D$ study. Journal of Affective Disorders 172: 96-102. Link: https://bit.ly/2YynI8F 
17. Fried E, Nesse R (2015) Depression sum-scores don't add up: Why analyzing specific deperssion symptoms is essential. Current Controversies in Psychiatry 13: 72. Link: https://bit.ly/2pt5iYV

18. Hasler G, Northoff G (2011) Discovering imaging endophenotypes for major depression. Molecular Psychiatry 16: 604-619. Link: https://go.nature.com/2Zm6Kvu

19. Beijers L, Wardenaar KJ, van Loo HM, Schoevers RA (2019) Data-driven biological subtypes of depression: systematic review of biological approaches to depression subtyping. Molecular Psychiatry. Link: https://go.nature.com/2Mn0cZU

20. Wardenaar K, Conradi Hj, De Jonge P (2014) Data-driven course trajectories in primary care patients with Major Depressive Disorder. Depression and Anxiety 31: 778-786. Link: https://bit.ly/2YfqRit

21. Hanna M. van Loo, Tianxi Cai, Michael J. Gruber, Junlong Li, Peter de Jonge et al. (2014) Major Depressive Disorder Subtypes to predict long-term course Depression and Anxiety 31: 765-777. Link: https://bit.ly/2SS5Pk4

22. Der-Avakian A, Matkou A (2012) The neurobiology of anhedonia and other reward-related deficits. Trends in Neurosciences 35: 68-77. Link: https://bit.ly/32YKc6q

23. Gold P, Chrousos G (2013) Melancholic and atypical subtypes of depression represent distinct pathophysiological entities: $\mathrm{CRH}$, neural circuits, and the diathesis for anxiety and depression. Molecular Psychiatry 18: 632-634. Link: https://bit.ly/2K4RDBJ

24. Sharpley C, Bitsika V (2013) Differences in neurobiological pathways of four "clinical content" subtypes of depression. Behavioural Brain Research 256: 368-376. Link: https://bit.ly/2YxLTYV

25. Ballard ED, Yarrington JS, Farmer CA, Lener MS, Kadriu B et al. (2018) Parsing the heterogeneity of depression: An exploratory factor analysis across commonly used depression rating scales. Journal of Affective Disorders 231 51-57. Link: https://bit.ly/2Gzz2eU

26. Sharpley C, Bitsika V (2014) Validity, reliability and prevalence of four 'Clinical Content' subtypes of depression Behavioural Brain Research 259: 9-15. Link: https://bit.ly/2YxLTYV

27. Sharpley C, Hussain R, Wark S G, Bitsika V, Mcevoy M (2017) Prevalence of depressed mood versus anhedonia in older persons: Implications for clinica practice. Asia Pacific Journal of Counselling and Psychotherapy 8: 3-14. Link: https://bit.ly/2KkJcR

28. Sharpley C, Bitsika V, Jesulola E, Fitzpatrick K, Agnew L (2016) The association between aspects of Psychological Resilience and subtypes of Depression: Implications for focussed clinical treatment models. International Journal of Psychiatry in Clinical Practice 20: 151-156. Link: https://bit.ly/2SThFuv

29. Chrousos G (2009) Stress and disorders of the stress system. Nature Reviews Endocrinology 5: 374-381. Link: https://bit.ly/2GyliQg

30. Steptoe A, Hamer M, Chida Y (2007) The effects of acute psychological stress on circulating inflammatory factors in humans: A review and meta-analysis. Brain, Behavior, and Immunity 21: 901-912. Link: https://bit.ly/2Yh1 o8i

31. Strain J (2018) The psychobiology of stress, depression, adjustment disorders and resilience. The World Journal of Biological Psychiatry 19: S14-S20. Link: https://bit.ly/330mKWq

32. Slavich G, Irwin M (2014) From stress to inflammation and major depressive disorder: A social signal transduction theory of depression. Psychological Bulletin 140: 774-815. Link: https://bit.ly/2KhgSiK

33. Caroline Menard, Madeline L. Pfau, Georgia E. Hodes, Veronika Kana, Victoria X. Wang et al. (2017) Social stress induces neurovascular pathology promoting depression. Nature Neuroscience 20: 1752-1760. Link: https://go.nature.com/331YMtE
34. Wan Mohd Yunus W, Musiat P, Brown J (2018) Systematic review of universa and targeted workplace interventions for depression. Occupational and Environmental Medicine 75: 66-75. Link: https://bit.ly/2K7hPvw

35. Iacovides A, Fountoulakis K, Kaprinis S, Kaprinis G (2003) The relationship between job stress, burnout and clinical depression. Journal of Affective Disorders 75: 209-221. Link: https://bit.ly/32ZqRSD

36. Madsen IEH, Nyberg ST, Magnusson Hanson LL, Ferrie JE, Ahola K et al (2017) Job strain as a risk factor for clinical depression: systematic review and meta-analysis with additional individual participant data. Psychological Medicine 47: 1342-1356. Link: https://bit.ly/2KaE3eN

37. Fairbrother K, Warn J (2003) Workplace dimensions, stress and job satisfaction. Journal of Managerial Psychology 18: 8-21. Link: https://bit.ly/2GBuKna

38. Archibald C (2006) Job satisfaction among neonatal nurses. Paediatric Nursing 32: 176-179. Link: https://bit.ly/2GyHsmA

39. Spector P (1997) Job Satisfaction: Application, Assessment, Causes and Consequences, London, UK, Sage. Link: https://bit.ly/2GF6v7s

40. Clegg C (1983) Psychology of employee lateness, absence and turnover: A methodological critique and empirical study. Journal of Applied Psychology 68: 88-101. Link: https://bit.ly/2Mpu0Ff

41. Jamal M (1984) The job stress and job performance controversy: An empirical assessment. Organizational Behavior and Human Performance 33 1-21. Link: https://bit.ly/2YxbOjF

42. Judge T, Watanabe S (1993) Another look at the job satisfaction-life satisfaction relationship. Journal of Applied Psychology 78: 939-948. Link: https://bit.ly/2Ykj3fH

43. Judge $T$, Weiss $H$, Kammeyer-Mueller D, Hulin C (2017) Job attitudes, job satisfaction, and job affect: A century of continuity and of change. Journal of Applied Psychology 102: 356-374. Link: https://bit.ly/20to15c

44. Anne Paula O'Keeffe MSc Nur (Dist), Margarita Corry MSc, Debra K. Moser DNSc (2015) Measuring job satisfaction of advanced nurse practitioners and advanced midwife practitioners in the Republic of Ireland: a survey. Journal of Nursing Management 23: 107-117. Link: https://bit.ly/32Xs6lc

45. Dekoulou P, Trivellas P (2015) Measuring the Impact of Learning Organization on Job Satisfaction and Individual Performance in Greek Advertising Sector. Procedia - Social and Behavioral Sciences 175: 367-375. Link: https://bit.ly/2SROVnF

46. Chen P, Sparrow P, Cooper C (2016) The relationship between personorganization fit and job satisfaction. Journal of Managerial Psychology 31 : 946-959. Link: https://bit.ly/32YGwSa

47. Wooden M, Watson N (2007) The HILDA survey and its contribution to economic and social research (so far). Economic Record, 83: 208-231. Link: https://bit.ly/2ynXLy9

48. Milner A, Niedhammer I, Chastang JF, Spittal MJ, LaMontagne AD (2016) Validity of a Job-Exposure Matrix for Psychosocial Job Stressors: Results from the Household Income and Labour Dynamics in Australia Survey. PLOS One 11. Link: https://bit.ly/2LLQHEd

49. Cohen J (1988) Statistical power for the behavioural sciences, Hillsdale, NJ, Erlbaun. Link: https://bit.ly/2H6Gz5h

50. ABS (2013) Australian and New Zealand Standard Classification of Occupations Version 1.2 In: STATISTICS, A. B. O. (ed.). Canberra: Australian Government. Link: https://bit.ly/2YtrhRL

51. Leach SL, Butterworth P, Rodgers B,Strazdins L ( 2010) Deriving an EvidenceBased Measure of Job Quality from the HILDA Survey. Australian Social Policy Journal Link: https://bit.ly/2YoYZYL 
52. Zung W (1965) A self-rating depression scale. Archives of General Psychiatry 12: 63-70. Link: https://bit.ly/2UFdYbX

53. Zung W (1973) From art to science: The diagnosis and treatment of depression. Archives of General Psychiatry 29: 328-337. Link: https://bit.ly/2K3jD8G

54. Dejonge J, Baneke J (1989) The Zung Self-rating Depression Scale: A replication study on reliability, validity and prediction. Psychological Reports 64: 833-834. Link: https://bit.ly/2SShaAK

55. Gabrys J, Peters K (1985) Reliability, discriminant and predictive validity of the Zung Self-Rating Depression Scale. Psychological Reports 57: 10911096. Link: https://bit.ly/2SSFItb

56. Schaefer A, Brown J, Watson C, Plenel D, Demotts J, et al. (1985) Comparison of the validities of the Beck, Zung and MMPI depression scales. Journal of Consulting and Clinical Psychology 53: 415-418. Link: https://bit.ly/2ZiLw10

57. Tabachnik B, Fidell L (2013) Using multivariate statistics, Boston, Pearson Education. Link: https://bit.ly/2HyTb6V

58. Strotz R, Wold H (1985) Recursive versus non-recursive systems: an attempt at synthesis. In: BLALOCK, H. (ed.) Causal models in the Social Sciences. London: aldine Link: https://bit.ly/2Ywn3F5

59. Chaouloff F (2000) Serotonin, stress and corticoids. Journal of Psychopharmacology 14: 139-151. Link: https://bit.ly/2ZjO0wQ

60. Maes M, Meltzer H (1995) The serotonin hypothesis of major depression In: BLOOM, F. E. \& KUPFER, D. J. (eds.) Psychopharmacology: The fourth generation of progress. New York: Raven.

61. Cools R, Robinson O, Sahakian B (2008) Acute tryptophan depletion in healthy volunteers enhances punishment prediction but does not affect reward prediction. Neuropsychopharmacology. 33: 2291-2299 Link: https://go.nature.com/2K5CD6s

62. Evers EA, Cools R, Clark L, van der Veen FM, Jolles J et al. (2005) Serotonergic modulation of prefrontal cortex during negative feedback in probabilistic reversal learning. Neuropsychopharmacology 30: 1138-1147. Link: https://bit.ly/32X3Aka

63. Bolling M, Kohlenberg R, Parker C (2000) Behavior Analysis and Depression In: DOUGHER, M. J. (ed.) Clinical Behavior Analysis. Reno, Nevada: Context Press 127-152. Link: https://bit.ly/2LPEHS2

64. Fournier JC, Derubeis RJ, Hollon SD, Dimidjian S, Amsterdam JD (2010) Antidepressant Drug Effects and Depression Severity: A Patient-Level MetaAnalysis. Journal of the American Medical Association 303: 47-53. Link: https://bit.ly/2ypFZL2

65. Moncrieff J, Wessely S, Hardy R (2010) Active placebo versus antidepressants for depression (Review). The Cochrane Collaboration 1-28. Link: https://bit.ly/2K4GaSu

66. Castren E (2013) Neuronal network plasticity and recovery from depression JAMA Psychiatry 70: 983-989 Link: https://bit.ly/2LLT3TL

67. Lerner D, Henke R (2008) What Does Research Tell Us About Depression Job Performance, and Work Productivity? Journal of Occupational and Environmental Medicine 50: 401-410. Link: https://bit.ly/2YroXrx

68. White M, Hill S, Mcgovern P, Mills C, Smeaton D (2003) 'High-performance' Management Practices, Working Hours and Work-Life Balance. British Journal of Industrial Relations 41: 175-195. Link: https://bit.ly/2yomX7R

69. Reynolds J (2005) In the Face of Conflict: Work-Life Conflict and Desired Work Hour Adjustments. Journal of Marriage and Family 67: 1313-1331. Link: https://bit.ly/3190rdJ
70. Mckee-Ryan F, Harvey J (2011) “I Have a Job, But ...": A Review of Underemployment. Journal of Management 37: 962-996. Link: https://bit.ly/2YAITuQ

71. Clark A (2005) Your Money or Your Life: Changing Job Quality in OECD Countries. British Journal of Industrial Relations 43: 377-400. Link: https://bit.ly/3135WMt

72. Mossholder K, Richardson H, Settoon R (2011) Human Resource Systems and Helping in Organizations: A Relational Perspective. Academy of Management Review 36: 33-52. Link:

73. Lee B, Wang J, Weststar J (2015) Work hour congruence: the effect on job satisfaction and absenteeism. The International Journal of Human Resource Management 26: 657-675. Link: https://bit.ly/2SQ50Ny

74. Goran A (2013) Diagnostic and statistical manual of mental disorders (5th ed.), Washington, DC. American Psychiatric Association. 51:61-64. Link: https://bit.ly/2MwhDqW

75. Cohen J, Cohen P, West S, Aiken LS (2003) Applied multiple regression/ correlation analysis for the behavioral sciences, Mahwah, NJ, Lawrence Erlbaum Associates. Link: https://bit.ly/312h1NZ

76. Norris A, Aroian K (2004) To transform or not transform skewed data for psychometric analysis: That is the question! Nursing Research 53: 67-71. Link: https://bit.ly/31avs9j

77. Pallant J (2011) SPSS Survival Manual (4rd ed.) Melbourne, Allen \& Unwin. Link: https://bit.ly/2Ytcq5H

78. Sharpley C, Bitsika V, Christie D (2009) Understanding the causes of depression among prostate cancer patients: Development of the Effects of Prostate Cancer on Lifestyle Questionnaire. Psycho-Oncology 18: 162-168. Link: https://bit.ly/2Zm0GmX

\section{Discover a bigger Impact and Visibility of your article publication with Peertechz Publications}

\footnotetext{
Highlights

* Signatory publisher of ORCID

* Signatory Publisher of DORA (San Francisco Declaration on Research Assessment)

* Articles archived in worlds' renowned service providers such as Portico, CNKI, AGRIS TDNet, Base (Bielefeld University Library), CrossRef, Scilit, J-Gate etc.

* Journals indexed in ICMJE, SHERPA/ROMEO, Google Scholar etc

* OAI-PMH (Open Archives Initiative Protocol for Metadata Harvesting)

* Dedicated Editorial Board for every journal

* Accurate and rapid peer-review process

* Increased citations of published articles through promotions

* Reduced timeline for article publication
}

Submit your articles and experience a new surge in publication services (https://www.peertechz.com/submission).

Peertechz journals wishes everlasting success in your every endeavours.

Copyright: @ 2019 Sharpley CF, et al. This is an open-access article distributed under the terms of the Creative Commons Attribution License, which permits unrestricted use, distribution, and reproduction in any medium, provided the original author and source are credited. 